\title{
Hubungan Gaya Koping Remaja dan Keterlibatan Orang Tua dengan Resiliensi pada Remaja Selama Pandemi COVID-19
}

\section{The Relationship between Adolescent Coping Style and Parental Involvement with Resilience in Adolescents During the COVID-19 Pandemic}

\author{
Resti Ikhda Syamsiah ${ }^{1 凶}$, Retno Lestari² ${ }^{2}$ Laily Yuliatun ${ }^{3}$ \\ 1Program Studi Magister Keperawatan Fakultas Kedokteran Universitas Brawijaya \\ 2,3Pengajar Fakultas Kedokteran Universitas Brawijaya
}

\begin{abstract}
ABSTRAK
Latar Belakang: Pandemi COVID-19 telah memberikan perubahan kehidupan secara drastis bagi seluruh populasi di dunia, termasuk remaja. Perubahan proses pembelajaran dari luring menjadi daring membuat remaja mengalami kehidupan yang penuh tekanan. Hasil studi pendahuluan menunjukkan tidak adanya keterlibatan orang tua selama pembelajaran daring $(85,2 \%)$. Penting bagi remaja untuk dapat beradaptasi dengan tantangan pembelajaran selama pandemi agar menjadi individu yang resilien.

Tujuan: Mengetahui hubungan gaya koping dan keterlibatan orang tua dengan resiliensi pada remaja selama pandemi COVID-19.

Metode: Desain penelitian ini menggunakan pendekatan analitik korelasional dengan responden 111 siswa Sekolah Menengah Atas (SMA). Lokasi penelitian dilaksanakan di SMAN 1 Jatilawang pada bulan Maret 2021. Analisis data multivariat menggunakan uji regresi linier.

Hasil: Hasil penelitian menunjukkan bahwa ada hubungan positif antara gaya koping dengan resiliensi pada remaja dengan $p<0.001$ dan ada hubungan negatif antara keterlibatan orang tua dengan resiliensi pada remaja dengan $p<0.001$. Gaya koping merupakan variabel yang paling berhubungan dengan resiliensi remaja dengan nilai standardized coefficient beta 0,773 .

Kesimpulan: Gaya koping dan keterlibatan orang tua berpengaruh terhadap resiliensi remaja. Gaya koping merupakan faktor penentu dalam proses adaptasi positif menghadapi stress dan trauma (resiliensi) remaja selama proses pembelajaran daring.
\end{abstract}

Kata Kunci: Gaya koping; Keterlibatan orang tua; Resiliensi; Remaja

\section{ABSTRACT}

Background: The COVID-19 pandemic has drastically changed the lives of the entire population in the world, including teenagers. The change in the offline learning process to online makes teenagers experience a stressful life. The results of the preliminary study showed that there was no parental involvement during online learning $(85.2 \%)$. It is important for teenagers to be able to adapt to the challenges of learning during a pandemic in order to become resilient individuals.

Objective: To determine the relationship of coping styles and parental involvement to resilience in adolescents during the COVID-19 pandemic.

Methods: This study used a correlational analytic research design with 111 high schools (SMA) students as respondents..The research location was carried out at SMA N 1 Jatilawang in March 2021. Multivariate analysis used linear regression test.

Results: The results showed that there was a positive relationship between coping styles and resilience in adolescents with $p<0.001$ and there was a negative relationship between parental involvement and resilience in adolescents with $p<0.001$ Coping style was the variable most related to adolescent resilience with a standardized coefficient beta value of 0.773 .

Conclusion: Coping style and parental involvement affect adolescent resilience.Coping style is a determining factor in the process of positive adaptation to stress and trauma (resilience) of adolescents during the online learning process.

Keywords: Coping style; Parental involvement; Resilience; Teenagers

$\llbracket$ Corresponding author: restiikhdasyamsiah@gmail.com

Diajukan 26 Juni 2021 Diperbaiki 1 Januari 2022 Diterima 28 Februari 2022

https://jurnal.ugm.ac.id/jkesvo Published online February 28, 2021 


\section{PENDAHULUAN}

Kondisi pandemi coronavirus disease (COVID 19) yang telah ditetapkan oleh WHO menunjukkan terjadinya peningkatan angka morbiditas dan mortalitas yang berdampak pada berbagai aspek kehidupan, seperti status kesehatan fisik dan mental, sosial, ekonomi, dan pendidikan (Ellis et al., 2020; Magson et al., 2020; Zhang et al., 2020). Adanya pembatasan kehidupan sosial selama pandemi memengaruhi dinamika kegiatan sehari-hari. Seluruh masyarakat tak terkecuali remaja harus tinggal di rumah dalam melakukan aktivitasnya (Janssen et al., 2020). Janssen et al., (2020) menjelaskan bahwa remaja mengalami kesulitan dalam mengatur emosinya saat harus bersosialisasi dengan keluarga.

Penelitian terdahulu juga menjelaskan tentang remaja yang mengalami kesulitan bersosialisasi secara langsung dengan teman seusianya (Magson et al., 2020), pertengkaran dengan keluarga (Pigaiani et al., 2020), lamanya masa pandemi COVID19 yang tidak pasti, proses pembelajaran yang berbeda dari luring menjadi daring, serta kurangnya aktivitas sosial dan fisik (Jeong et al., 2016; Zhang et al., 2020). Data hasil studi pendahuluan menunjukkan bahwa $55,7 \%$ siswa menganggap perubahan proses pembelajaran adalah masalah utama yang paling dirasakan selama pandemi.

Sekitar 47,7\% siswa beralih ke aktivitas lain untuk mengalihkan pikiran dan $42 \%$ siswa menyatakan tidak pernah memberitahu orang tua jika mereka mengalami masalah. Sebanyak 19,3\% siswa menyatakan tidak bisa bangkit kembali secara cepat setelah mengalami banyak tekanan. Selain itu, 21,6\% siswa merasa sulit untuk melewati kejadian yang memperberat kondisi psikologisnya.

Kekhawatiran remaja tentunya akan berpengaruh terhadap gaya koping yang ditampilkannya. Remaja yang memiliki gaya koping positif ditunjukkan dengan adanya berbagai aktivitas seperti: komunikasi dengan teman dan keluarga melalui panggilan video dan melakukan aktivitas yang menyenangkan (Branquinho et al., 2020; Diamond \& Willan, 2020).

Remaja yang memiliki gaya koping negatif selama pandemi ditunjukkan dengan adanya perilaku penghindaran, seperti menjaga perasaan untuk diri sendiri, menghindari situasi yang menimbulkan tekanan seperti penyangkalan, dan tetap tinggal jauh dari orang (Thompson et al., 2018). Hal tersebut dapat memengaruhi resiliensi pada remaja.

Keterlibatan orang tua juga dapat memengaruhi resiliensi remaja selama pandemi. Ketika remaja mendekati usia dewasa muda, keterlibatan orang tua cenderung berkurang karena remaja sudah mulai mengenali dirinya dan belajar mengambil keputusan (Costa \& Faria, 2017).

Berkurangnya keterlibatan orang tua dapat menjadi faktor risiko terjadinya masalah kesehatan mental dan dapat menghambat resiliensi remaja karena keterlibatan orang tua yang buruk (Old etal., 2018). Resiliensi telah ditentukan oleh American Psychological Association sebagai proses adaptasi yang baik dalam menghadapi kesulitan.

Menurut Howell et al., (2020), resiliensi dapat menentukan status kesehatan mental remaja di masa depan. Individu yang memiliki tingkat resiliensi lebih rendah akan berisiko mengalami masalah kesehatan mental, sedangkan individu dengan tingkat resiliensi yang tinggi akan memiliki kesehatan mental yang baik.

Mengetahui uraian masalah tersebut, penelitian ini difokuskan pada hubungan gaya koping remaja dan keterlibatan orang tua (parental involvement) dengan resiliensi pada remaja selama pandemi COVID-19 dengan mengambil lokasi di SMA N 1 Jatilawang. 


\section{METODE PENELITIAN}

Desain penelitian ini menggunakan pendekatan analitik korelasional. Populasi dalam penelitian ini yaitu semua siswa kelas $X$ dan XI di SMAN 1 Jatilawang. Jumlah responden kelas $X$ sebanyak 55 dan XI sebanyak 56. Total responden dalam penelitian berjumlah 111 siswa. Penelitian ini telah dilakukan pada bulan Maret 2021.

Teknik sampling yang digunakan yaitu probability sampling dengan cara stratified random sampling, yang merupakan cara pemilihan sampel dari populasi heterogen. Analisa bivariat menggunakan Korelasi Product Moment Pearson dan Spearman. Kriteria inklusi penelitian yaitu siswa kelas $\mathrm{X}$ dan kelas XI yang terpilih untuk menjadi responden sesuai dengan teknik probability sampling dan bersedia menjadi responden.

\section{HASIL DAN PEMBAHASAN}

\section{Analisis Univariat}

Penelitian ini mendeskripsikan tentang karakteristik responden yang meliputi jenis kelamin, kelas, tinggal bersama dan pendidikan orang tua. Berdasarkan tabel 1, jenis kelamin responden siswa dari penelitian mayoritas perempuan (78,4\%). Mayoritas responden tinggal bersama orang tua (82\%). Berdasarkan tingkat pendidikan orang tua siswa, sebagian besar menempuh pendidikan SMP (36\%).

Berdasarkan tabel 2 didapatkan bahwa mayoritas responden remaja dari penelitian memiliki gaya koping positif $(86,5 \%)$ dengan skor rata-rata 7,32 dan standar deviasi 6,414. Gaya koping positif dapat melindungi individu dari masalah kesehatan mental saat menghadapi keadaan darurat (Xu \& He, 2012).

Perilaku yang diadopsi oleh individu yang sedang menghadapi tekanan dan kemunduran untuk memperoleh keseimbangan di bawah tekanan merupakan pengertian dari gayakoping. Selain itu, gaya koping juga merupakan faktor penting yang digunakan untuk beradaptasi dengan lingkungan baru dan menjaga kesehatan mental yang positif (Early \& Grady, 2017).

Tabel 1. Distribusi Frekuensi dan Persentase Karakteristik Responden

\begin{tabular}{|c|c|c|c|}
\hline \multirow{3}{*}{$\frac{\text { No }}{1}$} & Karakteristik & $f(n=111)$ & $(\%)$ \\
\hline & Jenis kelamin & & \\
\hline & a. Laki-laki & 24 & 21,6 \\
\hline 1 & b. Perempuan & 87 & 78,4 \\
\hline \multirow[t]{3}{*}{2} & Kelas & & \\
\hline & a. X (sepuluh) & 55 & 49,5 \\
\hline & b. XI (sebelas) & 56 & 50,5 \\
\hline \multirow[t]{5}{*}{3} & Tinggal Bersama & & \\
\hline & a. Orang tua & 91 & 82 \\
\hline & $\begin{array}{l}\text { b. Keluarga dan salah satu } \\
\text { orang tua }\end{array}$ & 12 & 10,8 \\
\hline & c. Kakek dan nenek & 5 & 4,5 \\
\hline & d. Lainnya & 3 & 2,7 \\
\hline \multirow[t]{5}{*}{4} & Pendidikan orang tua & & \\
\hline & a. SD & 30 & 27 \\
\hline & b. SMP & 40 & 36 \\
\hline & c. SMA & 30 & 27 \\
\hline & d. Perguruan tinggi & 11 & 10 \\
\hline
\end{tabular}

Tabel 2. Distribusi Responden Berdasarkan Gaya Koping

\begin{tabular}{|c|c|c|c|c|c|}
\hline No & $\begin{array}{c}\text { Gaya } \\
\text { koping }\end{array}$ & $\mathbf{N}$ & $\%$ & Mean & $\begin{array}{c}\text { Std. } \\
\text { Deviation }\end{array}$ \\
\hline 1 & Positif & 95 & 86.5 & 7.32 & 6.414 \\
\hline 2 & Negatif & 15 & 13.5 & & \\
\hline
\end{tabular}

pembelajaran yang dilakukan secara daring, remaja mengalami kesulitan. Oleh karena itu, para remaja perlu mengatasi kesulitan tersebut dengan cara komunikasi reguler dengan teman dan keluarga melalui panggilan video serta melakukan aktivitas yang menyenangkan (misalnya, berolahraga, membaca, melatih, memainkan alat musik, bermain game, menonton serial televisi) (Branquinho et al., 2020).

Dalam penelitian ini, gaya koping positif yang dilakukan remaja seperti memperkuat agama, mencari dukungan, bersikap humor dan mencari hikmah di balik peristiwa yang terjadi. Sebanyak $13,5 \%$ remaja menggunakan gaya koping negatif berupa menyalahkan diri sendiri, menyalahkan situasi, menggunakan alkohol, menyerah serta bisa juga menghindari masalah. 
Tabel 3. Distribusi Responden Berdasarkan Keterlibatan Orang Tua

\begin{tabular}{clccc}
\hline No & \multicolumn{1}{c}{ Keterlibatan orang tua } & N & \% \\
\hline 1 & Baik & 25 & 22.5 \\
2 & Cukup & 42 & 37.8 \\
3 & Kurang baik & & 44 & 39.7 \\
\hline \multicolumn{2}{l}{ Berdasarkan tabel } & 3 & didapatkan
\end{tabular}

bahwa mayoritas remaja menyatakan keterlibatan orang tua kurang baik selama pandemi $(39,7 \%)$. Hasil tersebut sesuai dengan teori yang menjelaskan bahwa usia remaja siswa menengah memiliki keterlibatan orang tua dengan level terendah (Hornby \& Lafaele, 2011).

Keterlibatan orang tua adalah partisipasi kedua orang tua pada remaja dengan melakukan komunikasi yang bermakna terkait pembelajaran siswa dan kegiatan sekolah lainnya (Jeynes, 2017). Pada masa remaja, keterlibatan orang tua cenderung berkurang, seperti yang terjadi dalam penelitian ini.

Menurut Costa \& Faria (2017) ketika remaja mulai masuk sekolah menengah, orang tua berubah cenderung merasa tidak mampu memberi remaja bantuan di bidang akademik. Selain itu, orang tua juga tidak punya banyak waktu, dan ini adalah alasan utama kurangnya keterlibatan orang tua.

Indikator keterlibatan orang tua diklasifikasikan menjadi dua: pertama keterlibatan dan kedua komunikasi. Keterlibatan dapat dinilai dari pemanfaatan waktu luang, kesenangan, pengasuhan, perhatian tentang kegiatan sekolah serta mengembangkan kompetensi. Pada aspek komunikasi, hal yang dinilai seperti kedekatan, penghargaan, tekanan yang diberikan orang tua demi pengembangan diri remaja dan konflik yang dialami remaja dengan orang tua.

Tabel 4. Responden Berdasarkan Resiliensi

\begin{tabular}{llcccc}
\hline No & Resiliensi & N & $\%$ & Mean & $\begin{array}{c}\text { Std. } \\
\text { Deviation }\end{array}$ \\
\hline 1 & Rendah & 34 & 30.63 & 14.13 & 4.13 \\
2 & Sedang & 48 & 43.24 & & \\
3 & Tinggi & 29 & 26.13 & & \\
\hline
\end{tabular}

Resiliensi merupakan kondisi dimana seseorang dapat beradaptasi dan bertahan dari situasi sulit yang menyebabkan tekanan psikologis (Ran et al., 2020). Berdasarkan tabel 4 dapat diketahui bahwa tingkat resiliensi responden remaja mayoritas sedang $(43,24 \%)$ dengan skor rata-rata 14,13 dan standar deviasi 4,13.

Remaja dengan tingkat resiliensi yang rendah dalam penelitian ini cukup banyak yaitu $30,63 \%$ dan lebih banyak jika dibandingkan remaja yang memiliki resiliensi tinggi 26,13\%. Remaja dengan resiliensi tinggi mempunyai kemampuan yang baik untuk bangkit kembali dari situasi yang penuh tekanan selama pandemi COVID-19.

Remaja dengan resiliensi tinggi juga memiliki perilaku berisiko yang lebih rendah dan merasakan dampak dari pandemi COVID-19 lebih sedikit dari remaja yang mempunyai resiliensi rendah (Arslan \& Balkis, 2016; Paredes et al., 2021). Beberapa hal dapat memengaruhi tingkat resiliensi di antaranya faktor sosiodemografi (jenis kelamin, urutan kelahiran dan tingkat pendidikan orang tua), dukungan keluarga, keterlibatan orang tua, pendapatan rumah tangga, frekuensi Salat, dan juga optimisme (Killgore et al., 2020; Ran et al., 2020; Singh et al., 2019; Ungar \& Theron, 2020).

\section{Analisis Bivariat}

Dalam analisis bivariat, karakteristik responden yang dipakai seperti jenis kelamin, kelas responden, tinggal bersama dan pendidikan orang tua. Pada karakteristik tersebut dilakukan analisis bivariat seperti variabel gaya koping dan keterlibatan orang tua yang akan dihubungkan dengan resiliensi remaja. 
Tabel 5. Hasil Analisis Bivariat antara Karakteristik Responden, Gaya Koping Remaja dan Keterlibatan Orang Tua dengan Resiliensi Remaja

\begin{tabular}{llcc}
\hline No & Variabel & P & R \\
\hline 1 & Jenis kelamin & 0,892 & $-0,13$ \\
2 & Kelas & 0,057 & 0,181 \\
3 & Tinggal bersama & 0,911 & $-0,011$ \\
4 & Pendidikan orang tua & 0,000 & 0,675 \\
5 & Gaya koping & 0,000 & 0,632 \\
6 & Keterlibatan orang tua & 0,000 & $-0,477$ \\
\hline
\end{tabular}

Hubungan antara Jenis kelamin, Kelas, dan Tinggal Bersama dengan Resiliensi Remaja

Tabel 5 menunjukkan bahwa jenis kelamin, kelas dan tinggal bersama tidak berhubungan dengan resiliensi remaja karena $\mathrm{p}>0,05$. Jenis kelamin tidak berhubungan dengan resiliensi remaja dapat disebabkan karena jumlah antara laki-laki dan perempuan memiliki selisih yang banyak, yaitu 63 siswa.

Hal ini sejalan dengan penelitian sebelumnya yang menyatakan bahwa resiliensi tidak dipengaruhi oleh jenis kelamin atau perbedaan gender siswa SMA yang mayoritas sampelnya adalah perempuan (Chung \& Ho, 2017). Sunarti et al., (2018) juga menyatakan bahwa tidak ada perbedaan yang bermakna antara resiliensi remaja perempuan dan laki-laki $(p=0,067)$.

Dalam penelitian ini, kelas dan tinggal bersama juga tidak berhubungan dengan resiliensi ( $p=0,057 ; p=0,911$ ). Remaja yang tinggal bersama dengan orang tuanya belum tentu mempunyai resiliensi tinggi. Begitu pula dengan remaja yang hanya tinggal dengan ibu atau ayahnya saja dan dengan keluarga lainnya, belum tentu memiliki resiliensi yang rendah.

Hal tersebut dapat terjadi karena di masa pandemi penting bagi remaja untuk memiliki sikap dan komunikasi yang baik dengan lainnya, khususnya yang tinggal serumah dengannya agar tidak mengakibatkan konflik dalam keluarga. Seperti yang dijelaskan pada penelitian sebelumnya, masa remaja merupakan saat yang rentan berkonflik dengan orang tua, terbukti dari adanya peningkatan terjadinya konflik selama pandemi COVID-19 (Magson et al., 2020).

Hubungan antara Pendidikan Orang Tua, Gaya Koping dan Keterlibatan Orang Tua dengan Resiliensi Remaja

Variabel pendidikan orang tua dan gaya koping berhubungan signifikan dengan resiliensi remaja dengan $p<0,05$. Adanya hubungan yang kuat antara pendidikan orang tua dan gaya koping dengan resiliensi $(R=0,675$ dan 0,632$)$ dengan hubungan searah, memiliki arti makin tinggi pendidikan orang tua maka makin positif gaya koping, sehingga resiliensi remaja akan makin tinggi.

Hal itu sesuai dengan hasil penelitian sebelumnya, yaitu orang tua dengan tingkat pendidikan tinggi cenderung memberikan ilmu yang memuaskan, pekerjaan, serta masa depan interpersonal untuk buah hati mereka dari pada orang tua dengan pendidikan rendah. Hal tersebut yang membuat pendidikan orang tua berhubungan dengan resiliensi remaja karena dapat membantu remaja menghadapi tekanan hidupnya selama pandemi yang mengakibatkan remaja menjadi resilien.

Gaya koping juga memiliki hubungan positif yang kuat dengan resiliensi $(\mathrm{p}=$ 0,000 ). Mendukung penelitian lain dengan hasil adanya hubungan positif pada gaya koping dengan resiliensi remaja (Konaszewski et al., 2019). Remaja yang memiliki gaya koping positif akan memiliki tingkat resiliensi tinggi dan kesehatan mental yang baik dari pada remaja dengan gaya koping negatif ( $\mathrm{Wu}$ et al., 2020).

Hal tersebut dapat terjadi karena penggunaan strategi koping negatif yang menonjol cenderung menghambat adaptasi dan psikologis kesehatan (Cherry et al., 2017). Remaja yang menggunakan gaya koping negatif biasanya terjadi ketika ketangguhan yang dirasakan dan 
dukungan sosial seseorang tidak memadai dan ketika stres dianggap tidak terkendali (Thompson et al., 2018).

Hasil uji statistik pada variabel keterlibatan orang tua didapatkan $\mathrm{p}=$ $0,000<\mathrm{a}=0,005$, yang berarti bahwa ada hubungan yang signifikan antara keterlibatan orang tuadengan resiliensi. Nilai $R=-0,477$ menunjukkan bahwa arah hubungan variabel tersebut berlawanan. Artinya, jika keterlibatan orang tua tinggi, tingkat resiliensi remaja menjadi rendah. Sebaliknya, makin rendah keterlibatan orang tua, tingkat resiliensi akan makin tinggi.

Makin banyak skor keterlibatan orang tua menunjukkan makin sering orang tua berhubungan dan berkomunikasi dengan anak. Keterlibatan orang tua berupa pemberian tekanan pada remaja dapat memicu terjadinya konflik, mengingat masa remaja merupakan masa yang paling sering terjadi masalah dengan orang tua ataupun keluarga. Terbukti di masa pandemi ini konflik antara orang tua dengan remaja mengalami peningkatan (Magson et al., 2020).

Konflik yang terjadi antara orang tua dengan remaja akan membuat tekanan psikologis remaja meningkat dan mengalami stres yang akan membuat tingkat resiliensi remaja menjadi rendah. Kondisi pandemi juga membuat remaja mengalami peningkatan tekanan psikologi yang berhubungan negatif dengan tingkat resiliensi (Ran et al., 2020).

Pengalaman menyenangkan yang dialami remaja akan meningkatkan kesehatan mental dan membuat remaja menjadi resilien (Sunarti et al., 2018). Selain hal tersebut, hubungan negatif juga dapat disebabkan karena resiliensi dipengaruhi oleh banyak faktor, salah satunya oleh dukungan teman sebaya. Sesuai dengan penelitian sebelumnya yang menyatakan bahwa remaja yang mempunyai dukungan sosial dari teman seusianya akan memiliki tingkat resiliensi lebih tinggi sebanyak 2,723 kali dari pada remaja yang tidak mempunyai dukungan sosial (Mulia et al., 2014).

\section{Analisis Multivariat}

Tabel 6. Hasil Pemodelan Multivariat Regresi Linier Variabel yang Mempengaruhi Resiliensi Remaja

\begin{tabular}{llcccc}
\hline \multirow{2}{*}{ No } & Model & B & Beta & $\begin{array}{c}\text { Adjusted } \\
\boldsymbol{R}^{\mathbf{2}}\end{array}$ & $\begin{array}{c}\text { P- } \\
\text { value }\end{array}$ \\
\hline 1 & Konstanta & 8,499 & & 0,398 & 0,000 \\
2 & Gaya koping &, 498 & .773 & & \\
3 & $\begin{array}{l}\text { Keterlibatan } \\
\text { orang tua }\end{array}$ & .915 & .171 & & \\
\hline
\end{tabular}

Berikut hasil pemodelan akhir persamaan regresi linier.

Resiliensi $=8,49+0.49$ gaya koping remaja +0.91 keterlibatan orang tua

1. Nilai konstanta sebesar 8,49 yang dapat diartikan bahwa skor resiliensi akan bernilai 8,49 satuan jika variabel gaya koping dan keterlibatan orang tua tidak ada.

2. Gaya koping mempunyai nilai koefisien regresi yang positif yaitu sebesar 0,49. Hal ini menggambarkan bahwa jika terjadi kenaikan nilai gaya koping sebanyak satu persen maka akan menyebabkan kenaikan nilai resiliensi sebesar 0,49\%, dengan asumsi variabel keterlibatan orang tua dinilai konstan.

3. Keterlibatan orang tua mempunyai nilai koefisien regresi 0,91 sehingga jika nilai keterlibatan orang tua naik satu persen akan menimbulkan naiknya tingkat resiliensi sebanyak $0,91 \%$, dengan asumsi variabel gaya koping dinilai konstan.

Persamaan akhir pada hasil pemodelan multivariat digunakan untuk melakukan prediksi terhadap hubungan antara variabel yang mempengaruhi resiliensi remaja di SMA N 1 Jatilawang dalam pembelajaran daring selama masa pandemi COVID-19.

Tabel 6 juga menjelaskan bahwa nilai Adjusted $R$ Square adalah 0,398 yang mengandung arti bahwa sebesar 39,8\% tingkat resiliensi dipengaruhi oleh variabel gaya koping dan keterlibatan orang tua. 
Sisanya $60,2 \%$ dipengaruhi oleh faktor lain di luar model penelitian. Persamaan garis secara keseluruhan adalah signifikan $(\mathrm{p}=$ $0,000 ; \alpha=0,05)$. Variabel yang paling berhubungan dengan resiliensi remaja adalah gaya koping remaja $(\beta=0,773)$.

\section{Uji Asumsi}

\section{Uji Normalitas}

Hasil uji normalitas Kolmogorov Smirnov dengan $(n=111)$ didapatkan hasil dari variabel gaya koping dengan nilai $\mathrm{p}$ value $=0,264$ ) dan resiliensi remaja ( $\mathrm{p}$ value $=0,352)$. Artinya, nilai $\mathrm{p}>0,05$ sehingga dapat disimpulkan data tersebut terdistribusi normal.

\section{Asumsi Autokorelasi}

Nilai uji Durbin Watson didapatkan 2,066. Oleh karena itu, dapat disimpulkan bahwa du $<\mathrm{D}<$ (4-du) dengan nilai $1,72727<2,066<2,27273$ sehingga data tidak ada autokorelasi atau bebas dari autokorelasi.

\section{Asumsi Multikolinearitas}

Dari hasil analisis data didapatkan gaya koping remaja dan keterlibatan orang tua memiliki nilai VIF (Volume Inflation Factor) yang sama yaitu sebesar 3,1. Masing-masing variabel memiliki nilai toleransi pada kisaran angka $1-10$ yang artinya tidak terjadi multikolenieritas.

\section{Asumsi heteroskedastisitas}

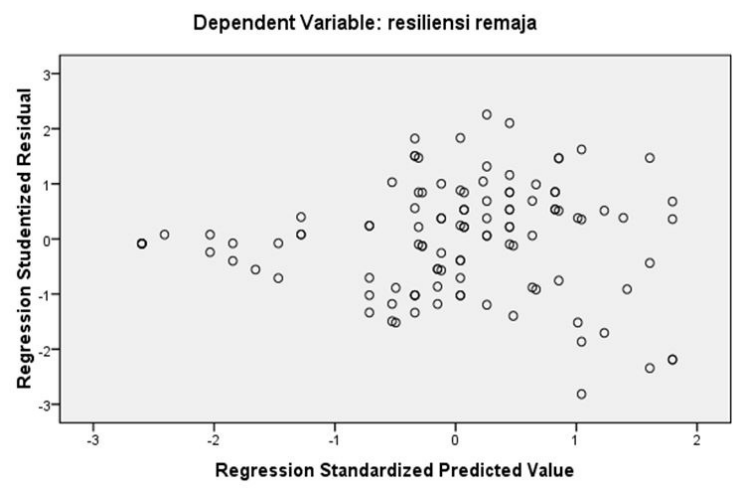

Gambar 1. Uji Heterokedastisitas

Gambar 1 menunjukkan bahwa titik pada scatter plot menyebar tanpa membentuk suatu pola. Data tersebar baik di kanan maupun di kiri angka 0 pada sumbu $X$. Itu berarti tidak terjadi heteroskedastisitas dalam model ini.

\section{Variabel yang Berhubungan Paling Dominan dengan Resiliensi Remaja}

Gaya koping merupakan variabel yang paling berhubungan dengan resiliensi remaja $(\beta=0,773)$. Makin tinggi skor gaya koping, tingkat resiliensi akan makin tinggi. Dalam penelitian ini remaja mayoritas memiliki gaya koping positif. Hal tersebut berarti bahwa remaja dalam menghadapi kesulitan atau tekanan selama pandemi mampu menghadapi dengan cara seperti mendalami agama, mencari dukungan, bersikap humor, dan mencari hikmah dari setiap kejadian yang telah terjadi.

Gaya koping positif dapat melindungi individu dari masalah kesehatan mental saat menghadapi keadaan darurat ( $\mathrm{Xu}$ \& $\mathrm{He}, 2012)$. Gaya koping yang positif sangat bermanfaat untuk mencapai kesehatan mental yang baik selama isolasi sosial COVID-19.

\section{KESIMPULAN}

Faktor risiko yang berhubungan dengan prosesresiliensi remaja selama pandemic diantaranya adalah Gaya koping remaja itu sendiri, Pendidikan orang tua serta adanya keterlibatan orang tua dalam mendampingi anak selama pembelajaran daring. Faktor lain seperti jenis kelamin, tempat tinggal dan hubungan antar remaja di kelas tidak berpengaruh terhadap kemampuan remaja melakukan adaptasi positif.

\section{SARAN}

\section{Sekolah}

Sebaiknya pihak sekolah membuat program untuk meningkatkan kesehatan mental remaja. Program yang dapat dilakukan berupa psiko-edukasi online terkait gaya koping dan resiliensi pada remaja. Selain itu, dapat membentuk kelompok dukungan teman sebaya yang 
memiliki permasalahan sama dengan melakukan kegiatan yang dievaluasi.

2. Perawat

Perawat sebaiknya bekerja sama dengan para guru untuk dapat memberikan intervensi yang bertujuan meningkatkan resiliensi pada remaja. Intervensi dapat disesuaikan dengan kondisi dan permasalahan yang dialami oleh remaja selama pandemi.

3. Orang tua

Memberikan perhatian dan dukungan penuh pada remaja dalam menjalani pendidikan daring selama pandemi COVID-19.

\section{DAFTAR PUSTAKA}

ARSLAN, G., \& BALKIS, M. (2016). Ergenlerde Duygusal İstismar, Problem Davranışlar, Öz-Yeterlik ve Psikolojik Sağlamlık Arasındaki İlişki. Sakarya University Journal of Education, 6(1), $\quad 8 . \quad$ https://doi.org/10.19126/ suje.35977

Branquinho, C., Kelly, C., Arevalo, L. C., Santos, A., \& Gaspar de Matos, M. (2020). "Hey, we also have something to say": A qualitative study of Portuguese adolescents' and young people's experiences under COVID19. Journal of Community Psychology, September,1-13.https://doi.org/10.1002/ jcop.22453

Cherry, K. E., Lyon, B. A., Sampson, L., Galea, S., Nezat, P. F., \& Marks, L. D. (2017). Prior Hurricane and Other Lifetime Trauma Predict Coping Style in Older Commercial Fishers After the BP Deepwater Horizon Oil Spill. Journal of Applied Biobehavioral Research, 22(2), 1-18. https://doi.org/10.1111/ jabr.12058

Chung, H., \& Ho, R. (2017). Impact of Parental Involvement , TeacherStudent Relationship, and Resilience on Academic Performance Among Middle School Students in Kang Won Province, in South Korea. Scholar: Human Sciencies, 8(2), 122-129.
Costa, M., \& Faria, L. (2017). Parenting and parental involvement in secondary school: Focus groups with adolescents' parents. Paideia, 27(67), 2836. https://doi.org/10.1590/198243272767201704

Diamond, R., \& Willan, J. (2020). Coronavirus disease 2019: achieving good mental health during social isolation. The British Journal of Psychiatry: The Journal of Mental Science, 217(2), 408-409. https://doi.org/ 10.1192/bjp.2020.91

Early, B. P., \& Grady, M. D. (2017). Embracing the Contribution of Both Behavioral and Cognitive Theories to Cognitive Behavioral Therapy: Maximizing the Richness. Clinical Social Work Journal, 45(1), 39-48. https:// doi.org/10.1007/s10615-016-0590-5

Ellis, W. E., Dumas, T. M., \& Forbes, L. M. (2020). Physically isolated but socially connected: Psychological adjustment and stress among adolescents during the initial COVID-19 crisis. Canadian Journal of Behavioural Science, 52(3), 177187. https://doi.org/10.1037/ cbs0000215

Hornby, G., \& Lafaele, R. (2011). Barriers to parental involvement in education: An explanatory model. Educational Review, 63(1), 37-52. https://doi.org/ 10.1080/00131911.2010.488049

Howell, K. H., Miller-Graff, L. E., Schaefer, L. M., \& Scrafford, K. E. (2020). Relational resilience as a potential mediator between adverse childhood experiences and prenatal depression. Journal of Health Psychology, 25(4), 545557.

$10.1177 / 1359105317723450$ https://doi.org/

Janssen Id, L. H. C., Kullberg 1, M.-L. J., Verkuil, B., Van Zwieten, N., Weverid, M. C. M., Van Houtumid, L. A. E. M., Wentholt, W. G. M., \& Elzinga, B. M. (2020). Does the COVID-19 pandemic impact parents' and adolescents' wellbeing? An EMA-study on daily affect and parenting. 1-22. https://doi.org/10.1371/ 
journal.pone.0240962

Jeong, H., Yim, H. W., Song, Y. J., Ki, M., Min, J. A., Cho, J., \& Chae, J. H. (2016). Mental health status of people isolated due to Middle East Respiratory Syndrome. Epidemiology and Health, 38, e2016048. https://doi.org/10.4178/ epih.e2016048

Jeynes, W. H. (2017). A Meta-Analysis: The Relationship Between Parental Involvement and Latino Student Outcomes. Education and Urban Society, 49(1), 4-28. https://doi.org/ 10.1177/0013124516630596

Killgore, W. D. S., Taylor, E. C., Cloonan, S. A., \& Dailey, N. S. (2020). Psychological resilience during the COVID-19 lockdown. Psychiatry Research, 291(May), 113216. https:// doi.org/10.1016/j.psychres.2020.113216

Konaszewski, K., Kolemba, M., \& Niesiobędzka, M. (2019). Resilience, sense of coherence and self-efficacy as predictors of stress coping style among university students. Current Psychology. https://doi.org/10.1007/ s12144-019-00363-1

Magson, N. R., Freeman, J. Y. A., Rapee, R. M., Richardson, C. E., Oar, E. L., \& Fardouly, J. (2020). Risk and Protective Factors for Prospective Changes in Adolescent Mental Health during the COVID-19 Pandemic. Journal of Youth and Adolescence. https:// doi.org/10.1007/s10964-020-01332-9

Mulia, L. O., Elita, V., \& Woferst, R. (2014). Hubungan Dukungan Sosial Teman Sebaya Terhadap Tingkat Resiliensi Remaja di Panti Asuhan. Journal Online Mahasiswa Program Studi Ilmu Keperawatan (JOM PSIK), 1(2), 1-9.

Old, J., Stevenson, A., Ortiz, E., \& Haley, B. (2018). Promoting or suppressing resilience to mental health outcomes in at risk young people: The role of parental and peer attachment and school connectedness. 64(April 2017), 13-22. https://doi.org/10.1016/ j.adolescence.2018.01.002
Paredes, M. R., Apaolaza, V., Fernandezrobin, C., Hartmann, P., \& Yañezmartinez, D. (2021). The impact of the COVID-19 pandemic on subjective mental well-being: The interplay of perceived threat, future anxiety and resilience. Personality and Individual Differences, 170(October 2020), 110455. https://doi.org/10.1016/ j.paid.2020.110455

Pigaiani, Y., Zoccante, L., Zocca, A., Arzenton, A., Menegolli, M., Fadel, S., Ruggeri, M., \& Colizzi, M. (2020). Adolescent Lifestyle Behaviors, Coping Strategies and Subjective Wellbeing during the COVID-19 Pandemic: An Online Student Survey. Healthcare, 8(4), 472. https://doi.org/ 10.3390/healthcare8040472

Ran, L., Wang, W., Ai, M., Kong, Y., Chen, J., \& Kuang, L. (2020). Psychological resilience, depression, anxiety, and somatization symptoms in response to COVID-19: A study of the general population in China at the peak of its epidemic. Social Science and Medicine, $262 . \quad$ https://doi.org/10.1016/ j.socscimed.2020.113261

Singh, R., Mahato, S., Singh, B., Thapa, J., \& Gartland, D. (2019). Resilience in nepalese adolescents: Sociodemographic factors associated with low resilience. Journal of Multidisciplinary Healthcare, 12, 893$902 . \quad$ https://doi.org/10.2147/ JMDH.S226011

Sprang, G., \& Silman, M. (2013). Posttraumatic stress disorder in parents and youth after health-related disasters. Disaster Medicine and Public Health Preparedness, 7(1), 105-110. https://doi.org/10.1017/dmp.2013.22

Sunarti, E., Islamia, I., Rochimah, N., \& Ulfa, M. (2018). Resiliensi Remaja: Perbedaan Berdasarkan Wilayah, Kemiskinan, Jenis Kelamin, dan Jenis Sekolah. Jurnal Ilmu Keluarga Dan Konsumen, 11(2), 157-168. https:// doi.org/10.24156/jikk.2018.11.2.157 
Thompson, N. J., Fiorillo, D., Rothbaum, B. O., Ressler, K. J., \& Michopoulos, V. (2018). Coping strategies as mediators in relation to resilience and posttraumatic stress disorder. Journal of Affective Disorders, 225, 153-159. https://doi.org/10.1016/ j.jad.2017.08.049

Ungar, M., \& Theron, L. (2020). Resilience and mental health: how multisystemic processes contribute to positive outcomes. The Lancet. Psychiatry, 7(5), 441-448. https://doi.org/10.1016/ S2215-0366(19)30434-1

Wu, Y., Yu, W., Wu, X., Wan, H., Wang, Y., \& Lu, G. (2020). Psychological resilience and positive coping styles among Chinese undergraduate students: A cross-sectional study. BMC Psychology, 8(1), 1-12. https:// doi.org/10.1186/s40359-020-00444-y

Xu, J., \& He, Y. (2012). Psychological health and coping strategy among survivors in the year following the 2008 Wenchuan earthquake. Psychiatry and Clinical Neurosciences, 66(3), 210219. https://doi.org/10.1111/j.14401819.2012.02331.x

Zhang, C., Ye, M., Fu, Y., Yang, M., Luo, F., Yuan, J., \& Tao, Q. (2020). The Psychological Impact of the COVID19 Pandemic on Teenagers in China. The Journal of Adolescent Health: Official Publication of the Society for Adolescent Medicine, December 2019. https:// doi.org/10.1016/ j.jadohealth.2020.08.026

Zhang, Q., Zhou, L., \& Xia, J. (2020). Impact of COVID-19 on emotional resilience and learning management of middle school students. Medical Science Monitor, 26, 1-9. https://doi.org/ 10.12659/MSM.924994 